\title{
Computational Making, Binary Gender and LEGO
}

\author{
Jennifer A. Rode \\ UCL Knowledge Lab \\ London, United Kingdom \\ j.rode@ucl.ac.uk
}

\author{
Veronica Cucuiat \\ UCL Knowledge Lab \\ London, United Kingdom \\ v.cucuiat.14@ucl.ac.uk
}

\begin{abstract}
This paper presents an analytical case study using the "Computational Making" framework to critique three LEGO sets. These sets were marketed towards girls and focus on making. Our contribution is showing computational making can be used to investigate domains outside e-textiles. Further, we show these LEGO sets have the potential to teach computational making skills despite their feminine gender identity construction.
\end{abstract}

\section{CCS CONCEPTS}

- Human-centered computing $\rightarrow$ Human computer interaction (HCI)

\section{KEYWORDS}

Computational Making, Computational Thinking, Gender, LEGO, children, STEAM, STEM, Science, Technology, Engineering, Arts Mathematics, Education

\section{ACM Reference format:}

Jennifer A. Rode, Veronica Cucuiat. 2018. Computational Making, Binary Gender and LEGO. In Proceedings of 4th Gender\&IT conference, Heilbronn, Germany, May 2018 (GenderIT'18), 8 pages. https://doi.org/10.1145/3196839.3196854

\section{INTRODUCTION}

The computational making framework [15] was developed to show how skills beyond those of computational thinking [20, 21] are required to engage in e-textiles. It was developed explicitly as a bi-product of exploring gender in making. In doing so it allowed Rode and colleagues to conclude that teaching computational making is critical to encouraging diversity in STEAM (Science, Technology, Engineering, Arts and Mathematics). However, it has not been applied to other domains. We wanted to explore other tools and see if this posed a useful framework around which to structure ongoing discussions of gender and making.

We chose computational making to investigate building with LEGO, given popular culture discussions of gender and education that surround them [2,9,15]. Starting with Papert [14] and continuing with Giddings [6] research findings continue to

Permission to make digital or hard copies of all or part of this work for personal or classroom use is granted withou fee provided that copies are not made or distributed for profit or commercial advantage and that copies bear this notice and the full citation on the first page. Copyrights for components of this work owned by others than ACM must be honored. Abstracting with credit is permitted. To copy otherwise, or republish, to post on servers or to redistribute to lists, requires prior specific permission and/or a fee. Request permissions from Permissions@acm.org. support the educational benefits for children when building with LEGO sets. However, sets which have been built with a more feminine target audience in mind have been criticized for the stereotyping and sexualizing of young girls [2,7,16]. Knudsen et al. [7] talk about "adults who expect the toys they purchase to ameliorate their own anxieties about the socializing effects of these toys and to proactively shape a more gender-neutral world." Despite this extensive critique that these sets reify binary gender roles for appropriate interests and behavior, we were unable to find literature that critiqued the educational value of these sets. Black et al. [2] investigated the correlation between LEGO themes, gendered discourse and the number of pieces which make up various sets, leading them to comment "LEGO is treating girls as more developmentally advanced than boys" [2]. However, they did not discuss the types of educational experiences children garner from play. This lack of research on LEGO sets marked toward girls was surprising as the first author is regularly asked to critique these sets from a feminist perspective. Surely, Lego kits marketed toward girls deserve the same serious study for their potential to teach computational making as much as any set?

This paper presents a case study examining the applicability of the computational making framework to LEGO kits marketed towards girls. Thus, here we review three kits in the context of the five core computational making skills identified by Rode et al. [15], used in the evaluation of learning opportunities in STEAM subjects and making: aesthetics, creativity, constructive, visualizing multiple representations and understanding materials. We aim to prove that the framework outlined by Rode et al. [15] is suitable for the analysis of STEAM oriented educational play, rather than it only being applicable to the limited domain of etextiles where it has been previously applied. We argue that from a computational making perspective, the three sets, marketed towards girls, have the same educational potential. Next, we discuss positioning computational making in terms of the social debate regarding limitations of binary gender identity formation.

The contribution of this paper is two-fold: firstly, we show that the "Computational Making" framework can be used to explore teaching of STEAM skills in a variety of educational making settings. Secondly, through this type of analysis of LEGO we show that despite criticism of their embedding gender stereotypes, they still hold potential to teach computational making skills. 


\section{COMPUTATIONAL THINKING AND MAKING}

We extend this analysis to the specific potential computational making skills perceived to be held by 'girly' LEGO sets. Computational thinking has been discussed by Kafai and colleagues [9] as a way of understanding maker cultures role in computing education. In this paper, we use Rode's et al.'s [15] theory of computational making to evaluate the educational benefits of three LEGO sets. Computational making builds on computational thinking which can be traced back to Papert in the 80s [14] and was popularized by Wing [20,21]. Barr and Stephenson [1], who operationalized it for K-12 teaching in the US curriculum, broke it down as a problem-solving process with the following components:

Analysing and organizing data logically;

Visualizing data though abstractions, modelling and simulations;

Formulating problems in a way a computer can help in solving them;

Identifying, analysing, and implementing solutions effectively and efficiently;

Using algorithmic thinking to automate solutions;

Generalizing and applying this problem-solving process to other kind of problems.

Rode et al. [15] found this definition appropriate for desktop computing ,but in their study of classroom making found it did not address all the skills with which learners were having difficulty. In 2016 Rode et al. proposed a new theory of computational making to extend computational thinking to include five new core skills to allow for the evaluation of learning opportunities in STEAM and making [15]. Rode et al. argued that while computational thinking skills were adequate for STEM projects, one needed to additionally consider computational making skills for STEAM based projects given their focus on arts and tangible making. These skills included aesthetics, creativity, constructing, visualizing multiple representation and understanding materials, which we will define next.

\subsection{Aesthetics}

Rode et al. [15], cite Kafai et al. [9], and Weibert et al. [18,19] in their use of aesthetics. Their usage of the term focuses on making technologies "aesthetically pleasing" [15]. This is of course, a reductive definition of aesthetics. Sean Cubitt defines digital aesthetics as a mediated experience of time [4], which is to say aesthetics goes beyond merely look and feel, rather it is the user's experience as they engage with the interface including that which lies under its "glossy exterior" [17]. This means aesthetics would also include the values and cultural import behind the interface.

\subsection{Creativity}

Rode et al. described, "creativity as a problem-solving tool as well as a tool for free expression - a form of skill building that allows for playful interpretive flexibility" [15].

\subsection{Constructing}

Rode et al. describe constructing as the skills required to make tangible objects. In the context of the e-textile project activities they identified "a variety of physical skills are required, among them sewing, soldering, using pliers, wire strippers, and other hand tools including scissors" [15]. Several challenges were observed as the children grasped such construction concepts. Practical difficulties occurred due to lack of dexterity using incorrectly sized tools as well as unfamiliarity with handling needles and thread required for sewing. Short circuits or poorly designed circuits presented logistical challenges, that were ultimately overcome.

\subsection{Visualizing Multiple Representations}

Through their experiments, Rode et al. identified a number of challenges children encountered when working with a $2 \mathrm{~d}$ and $3 \mathrm{~d}$ representations of circuits [15]. Children initially struggled seeing the relationship between a hand drawn circuit diagram and the same circuit built with components. Over the course of the projects children's understandings improved by labeling circuit traces, allowing them to move from schematics to connected components. Children demonstrated competency by being able to explain identified properties and behaviors to each other without adult guidance.

\subsection{Understanding Materials}

Children had difficulty understanding the properties of the material with which they were work working. For instance, materials such as conductive thread and fabrics, as well as, wire and alligator clips, all could carry current through a circuit. Thus, they could be used to connect a circuit or to inadvertently short one. At the same time these materials had different resistances, and voltages which were required to generate the same current.

Having discussed the five aspects of computational making, next we will discuss our selection criteria for choosing the LEGO sets and how they were analyzed.

\section{LEGO CASE STUDIES}

This paper will evaluate three sets in the LEGO lines marketed for girls as cases studies exploring the computational making framework. Black et al. eloquently describe the relevance of studying LEGO in the context of gender, "The creative, openended, and child-driven aspect of LEGO toys and media is crucial for understanding the full scope of play and learning afforded by the brand. However, because LEGO permeates the home and school lives of many young children who are actively developing cultural models associated with constructs such as gender, race, and social class, it is also crucial to attend to the brand-driven cultural practices and forms of play that are embedded in LEGO products through the company's processes of designing, manufacturing, and marketing." [2] When the Friends line was released, the brand quickly garnered strong proponents and detractors in the online community, with some praising LEGO's promotion of 'good role models for girls' [2] and others damning 
the sets as 'a pink and purple, gender segregated, suburban wasteland populated by Barbie/Bratz style dolls' [16].

Thus, we chose to focus on femininely gender LEGO sets. The three LEGO sets selected for this analysis are identifiable as 'girly' by the design decision to replace standard LEGO minifigures with LEGO "minidolls" [16]. A minidoll is less square than the standard minifigure with noticeable curves at the hip and bust. The hands and hair are on the same scale, but the head, torso and legs are not compatible size wise between the two figure types. Further, the minidolls are 5 bricks tall as opposed to the minifigures at approximately 4 bricks. This means the scale of the furniture, accessories and buildings are diffident which relegates minidolls and minifigures to separate worlds.

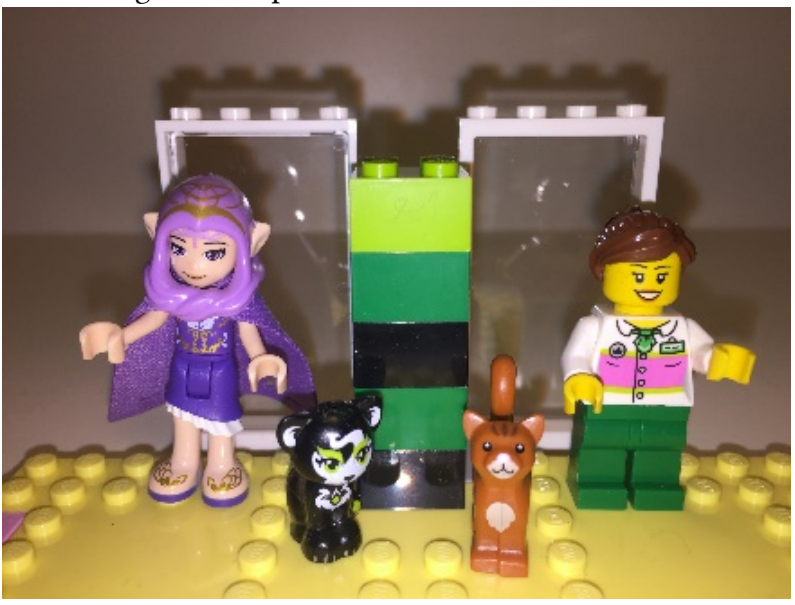

Figure 1. LEGO minidoll (left) and minifigure (right). Note shape and scale differences between the two in relation to the middle brick tower, door height and pet cats. (photo by authors)

The three sets selected were:

LEGO Friends- Fusion Resort Designer (set 21208)

LEGO Elves- Elvendale School of Dragons (set 41173)

LEGO Friends- Olivia's Creative Lab (set 41307)

Next, we will describe each of the sets, their storyline and how they emphasize computational making skills.

The sets are marketed for 7 to 12-year-old children, with Oliva's Creative Lab being for children as young as 5 . All sets are small containing under 300 pieces, making them some of the most affordable thus most accessible to children of disparate socioeconomic backgrounds. All sets were released in the last two years.

Table 1: LEGO sets in terms of targeted ages, number of pieces, and cost

\begin{tabular}{llll}
\hline & Age & Number of Pieces & Cost \\
\hline 21208 & $7-12$ & 263 & $\$ 19.99$ \\
41173 & $7-12$ & 230 & $\$ 19.99$ \\
41307 & $5-12$ & 91 & $\$ 9.99$ \\
\hline
\end{tabular}

\subsection{LEGO Friends- Fusion Resort Designer}

In the LEGO Friends Fusion Resort Designer children build a flat 2-dimensional building facade on a small plate. The structure is a maximum of $12 \times 16$ bricks. Next, children download and install the LEGO Fusion Resort App on a cell phone or tablet where they can customize their design, avatars, and take pictures of the structure.

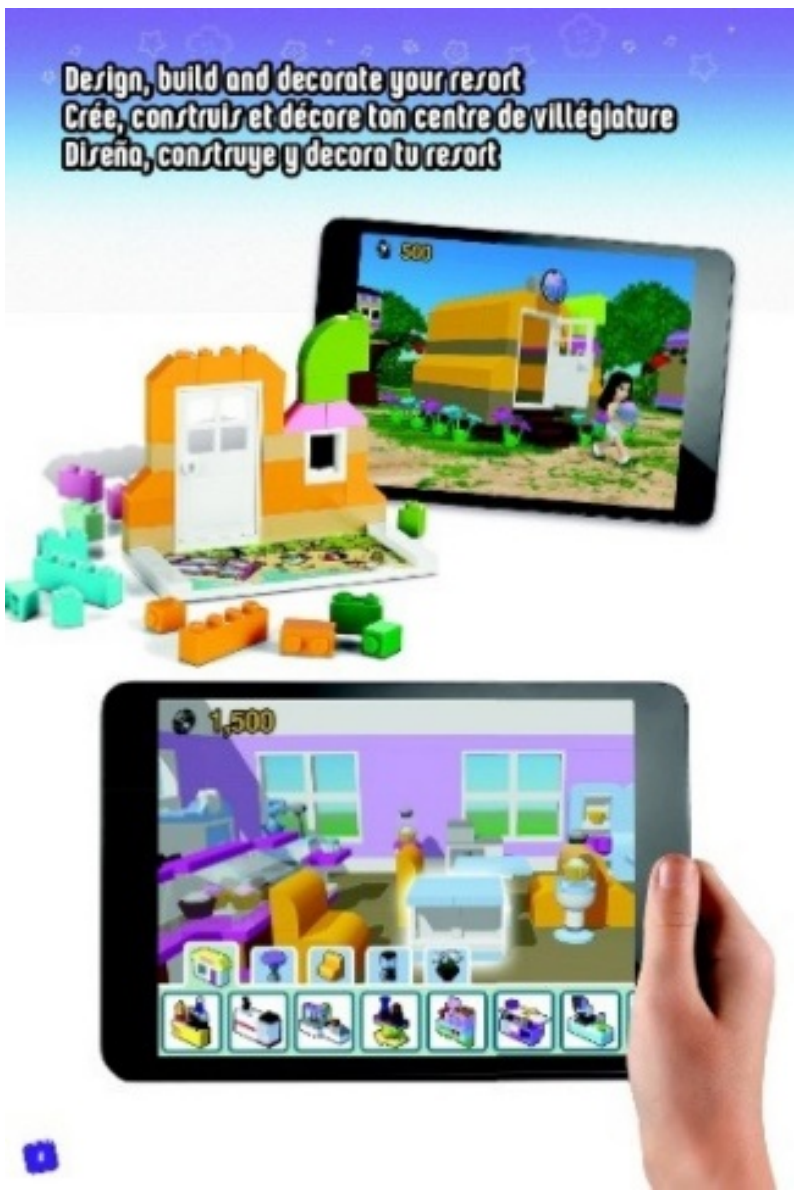

Figure 2. Instructions for Friends' LEGO Fusion Resort Designer [10].

The building is then extruded from a $2 \mathrm{~d}$ to a $3 \mathrm{~d}$ structure as the LEGO Friends character builds the new structure. The brick recognition algorithm can only work with the bricks provided in the kit, and even then, requires significant finesse to capture the image. Next, the structure is oriented and placed in a virtual resort world. Finally, the app is used to build out the inside of the building, by constructing virtual LEGO brick furnishings and decor including tables, chairs and counters. When the building is complete, other characters compel the player as part of the game narrative to build other structures for an unmet need in the resort - an ice cream parlor, a pizza shop, a souvenir shop or an animal hospital - at which point the process repeats. 


\subsection{LEGO Elves - Elvendale School of Dragons}

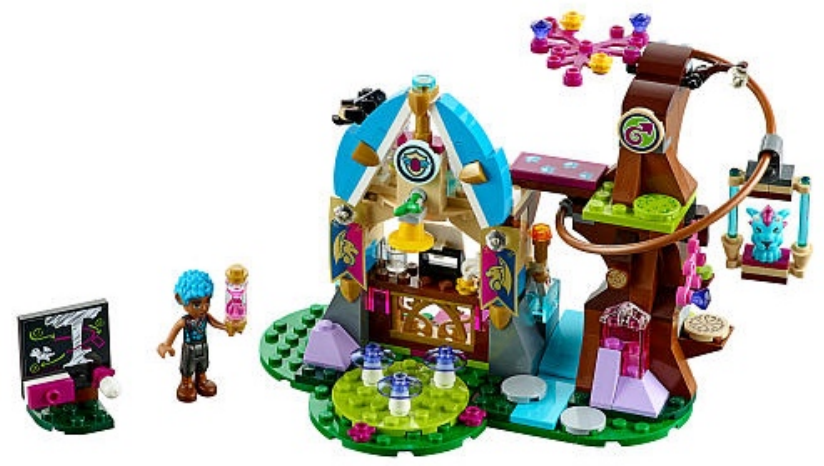

Figure 3: LEGO Elves Elvendale School of Dragons [11].

The LEGO Elves Elvendale School of Dragons is a school where Tidus, the dragon schoolteacher, teaches baby dragons how to fly. Notably unlike the Friends line a feature character, Tidus, is male. The set consists of a classroom replete with blackboard, lectern and mushroom stools for the dragons to use while listening to flying lectures. In a constructivist fashion the dragons are also encouraged to learn by doing, using a zip line mechanism which helps give them gather momentum, assisted by a breaking device. Finally, the baby dragon can be motivated to fly with a crossbow that shoots cookies.

\subsection{LEGO Friends - Olivia's Creative Club}

This set is Oliva's small lab for building three robots. It includes a workbench, tools, a parts box, schematic, three robots and a charging station for the robots complete with monitor. The Oliva character is described on the LEGO Friends wiki as "a little shy, but is very sweet and is also smart and creative. She loves science, especially geology, and technology, and enjoys doing experiments and inventing" [12]. Here you are invited to help Olivia follow the schematic and build a robot family, and then recharge, repair and rebuild it.

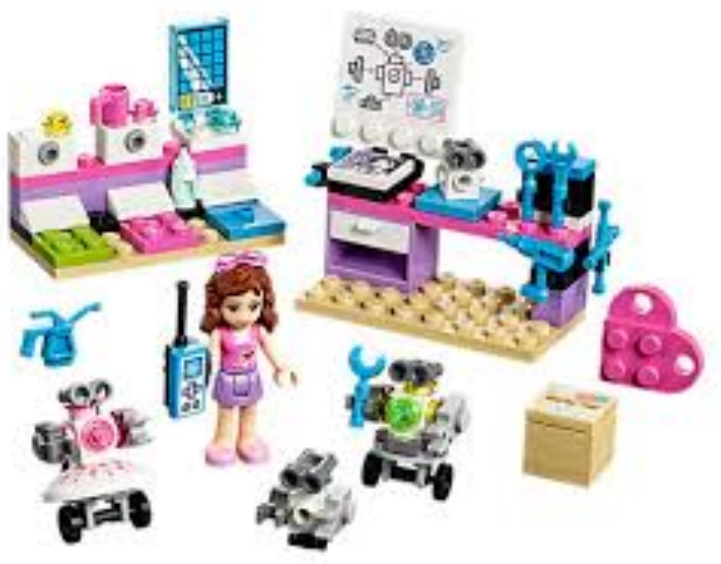

Figure 4: LEGO Friends- Olivia's Creative Lab [12].

\section{METHOD}

The authors assembled all three sets as per the instructions. To ensure we were correctly assembling them we watched the top three YouTube hits for each set. Our corpus included" "speed build" unboxing videos where individuals assembled the sets, providing commentary as well as product reviews. We did not perform content analysis, rather we watched the videos only to understand how the product was assembled. We wanted to make sure we had assembled them correctly.

We had initially hoped do a content analysis of mistakes made by children. However, the sets were so simple no mistakes were made (though perhaps they were edited out). Thus, the scope of the present analysis focused on analyzing the potential for teaching computational making. The videos provided merely provided confirmation of our correct assembly. Consequently, only three videos for each set were used due to the highly repetitive content. For the Fusion set we used the top three videos that included the physical brick build as opposed to ones that focused only on the onscreen game. We did not include any official LEGO videos in our corpus. The videos were shot such that we could not see the builder. Given that we were not focused on proving LEGO's effectiveness as an educational tool the videos were sufficient and appropriate.

LEGO Elves. 2017. Elvendale School of Dragons Build Review Silly Play Kids Toy. Video. (08 January 2017.). Retrieved January 30, 2017 from https://www.youtube.com/watch?v=X5NjzOC_NIA

LEGO Elves. 2016. Elvendale School of Dragons - Lego Speed Build. Video. (02 August 2016.). Retrieved January 30, 2017 from https://www.youtube.com/watch?v=Y74OBCtk6CU

LEGO Elves. 2016. Elvendale School of Dragons review! Video. (31 March 2016.). Retrieved January 30, 2017 from https://www.youtube.com/watch?v=Dd1XuosLQYE

LEGO Fusion. 2014. Friends Resort Designer Build with Level 1 Walkthrough. Video. (01 September 2014.). Retrieved January 30, 2017 from https://www.youtube.com/watch?v=j2ZLntxcotE

LEGO Fusion. 2015. RethinkTOYS. Video. (17 February 2015.). Retrieved January 30, 2017 from https://www.youtube.com/watch?v=O3tXa7w_guI 
Once we assembled the sets we looked for places where the various computational making skills could be taught. We did this much the same way teachers look for opportunities to provide practical examples to reinforce skills as part of their lesson. Our analysis is focused on whether the sets allow the possibility of teaching computational making skills. This is not an empirical analysis of the building process - the ease of use or challenges users go through to build these sets are not of interest for the current study. Determining that these skills are effectively taught is out of scope for this paper. In our discussion we will call for the need for additional future work to study whether LEGO is in fact able to effectively teach these computational making skills to girls.

In this way we obtained a complete understanding of how to build the sets informing our analysis of computational making. Rode et al. had previously laid out criteria for computational making through the creation of grounded theory [15]. Thus, while building the sets and watching the videos we looked for places where these computational making approaches were applied.

\section{COMPUTATIONAL MAKING THROUGH LEGO}

The LEGO sets allow for opportunity to explore all aspects of computational making including aesthetics, creativity, constructing, visualizing multiple representations and understanding materials.

\subsection{Aesthetics}

Given the above definition aesthetics is not just about appearance judgements. The sets allow children to make aesthetic decisions. For instance, in Olivia's Creative Lab the instructions show you how to build three robots: a baby robot with a bottle, a green robot with a wrench, and a pink robot with a pink polka dot skirt and a pink mug. They are building a robot family that replicates normative binary gender stereotypes in ways many might see as problematic - a mom washing dishes and feeding baby, and a dad building things. Children can choose to subvert these gender roles intentionally in their designs and in doing so are making aesthetic decisions. This might be as simple as mixing up the colors to make two female robots (two mommies) or giving the "girl" robot tools and the "boy" robot dishes. Thus, they move beyond the "glossy exterior" [17] of the robots, to engage in aesthetic decisions dealing with the values and cultural import behind their LEGO build.

\subsection{Creativity}

Rode et al. described, "creativity as a problem-solving tool as well as a tool for free expression - a form of skill building that allows for playful interpretive flexibility" [15]. They found children often found it difficult to express themselves by personalizing the projects. When children follow LEGO instructions verbatim they have no opportunity for creative expression. In Olivia's Creative Lab children can personalize the robots, which not only allows for aesthetic decisions but expression of creativity as discussed extensively elsewhere [15].
The Friend's LEGO Fusion Resort Designer tries to encourage children to push past merely following instructions via the app, which requires children to create multiple buildings for various for their resort-for instance characters in the storyline requesting an ice cream parlor or a pizza shop. The instructions provide pictures of sixteen sample buildings, but no step by step instructions. The set provides children a building platform which limits constructions to 12 bricks wide, a fixed set of bricks, and an explicit limitation of a maximum structure height of 16 bricks. In setting these limitations, the possibilities are constrained. This makes the task more manageable, increasing the opportunities for creative play.

\subsection{Constructing}

The easy entry point of building with LEGO bricks reduces the construction challenges. Using very basic math and minimal calculations children can visualize proportions, building planes and spaces of various structures given strict ratios between block sizes and a building grid that encourages relative placement to a Cartesian plane (place the $1 \times 2$ brick three blocks over and two blocks up in a horizontal orientation).

In the Fusion Resort Designer kit, children help the Olivia LEGO character build what her friends need in the resort - houses, shops, restaurants, juice bars and more. The kit includes 262 LEGO pieces for the physical construction of the basic resort, after which children are guided to continue their construction digitally via the LEGO Fusion Resort Designer app. The Fusion Resort Designer kit leverages the benefits of physical LEGO constructions digitally by allowing children to visualize their artifact via the app and continue building on it. The transition from the physical to the digital space using the 3D model of the initial construction allows children to better conceptualize the space and dimensions presented in the app. The children then enhance the physical structures by virtually decorating the interior of the rooms, thus extending their exploration of space proportions and planes in the digital app.

The Elvendale School of Dragons is an entirely physical construction LEGO kit, enabling children to build a dragon school where a baby dragon learns how to fly using a zip line. The kit contains highly detailed elements including a classroom, climbing tree, zip line for practice flights, blackboard, magic hourglass, cookie shooter and other accessories. Each individual element, as well as, the overall LEGO set is dynamically manipulatable and requires each individual part to be built correctly in order to work properly. The construction set is based on engineering concepts, using acceleration, and gravity to enable a baby dragon to fly using the zip line or to shoot the cookie. Additionally, the plant covering hiding place in the cave and school bell teach about axes and rotation.

Using the third LEGO kit, Olivia's Creative Lab, children construct a laboratory for Olivia to build her family of robots. Children get introduced to various lab accessories as well as the components which make up the robots. The laboratory contains technical equipment relevant for robots such as charging stations, as well as a robot remote control. The kits are designed to be approachable and enhance the construction confidence of 
children, empowering them to easily build meaningful and playful artifacts, and extending it to the digital space in the case of the Friends Fusion Kit.

\subsection{Visualizing Multiple Representations}

In our earlier work with e-textiles we recognized how children had difficulty going from $2 \mathrm{~d}$ circuit diagrams to making $3 \mathrm{~d}$ objects [15]. Thus, developing skills to read schematics is core to computational making.

Both Oliva's Creative Lab, and the Elvendale School for Dragons, and indeed all LEGO sets, contain step by step building instructions that teach children how to tackle the problem of building their project. The instructions themselves ramp up with Junior sets having both fewer number of pieces and overall steps than Expert sets. It also holds that the number of individual bricks placed per step increases for sets aimed towards older children.

More recent sets like the Oliva's Creative Lab, and the Elvendale School for Dragons not only contain a picture of the final kit in the instructions, but a blackboard shaped brick with a schematic of the planned project. In the case of the Elvendale School for Dragons set, there is a chalkboard explaining the mechanism catapulting the dragons into the air so they can practice flying. In the case of Oliva's Creative Lab there is a blueprint with an illustration of how to construct the robot. In both cases these schematics invite children to play act and instruct building thereby developing literacy with schematics and 2 and $3 \mathrm{~d}$ representations.

Friend's LEGO Fusion Resort Designer allows children to explicitly interact with 2 and $3 \mathrm{~d}$ representations. By making $2 \mathrm{~d}$ shapes and extruding them into $3 \mathrm{~d}$, and then having the opportunity to move the construction around in a $3 \mathrm{~d}$ space the child can explicitly build linkages visualizing multiple representations and inducing develop important skills in terms of computational making.

\subsection{Understanding Materials}

Finally, the last aspect of computational making that LEGO enables is understanding materials. Most LEGO bricks are rigid with a peg on top and a receptacle to receive the peg on the bottom. This limits the range of interaction with the materialsstacking upwards is the only possibility with the basic brick. However, there is some variation as shown in Figure 5a, here you can see that the regular brick (on the right) is the same height as three of the flat bricks called plates. Thus, they can be combined in flexible ways to allow increased variety. Additionally, some bricks have nobs on the front which permit flipping on their side to build on the front of the structure, as is the case with the chalkboard in the Elvendale School of Dragons. Similarly, hinged pieces allow for structures to be built on angle relative to the main structure, as is the case in the roofline of the Elvendale School of Dragons.

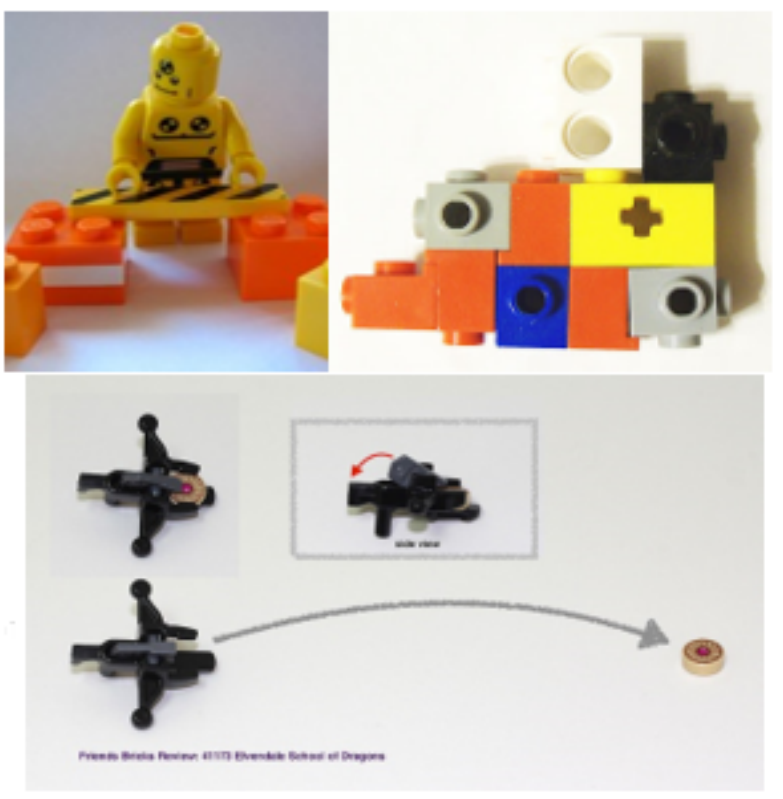

Figure 5: (a) Three plates are equivalent to one brick in height. (b) Using LEGO bricks with knobs on the side to building in different directions, as opposed to only vertically. (c) The cookie shooter's firing sequence [3].

Other materials are not rigid and can be manipulated as such. The plastic banners can be bent to simulate movement in the wind. The zip line in the LEGO Elves Elvendale School of Dragons is made of a brown $16 \mathrm{~cm}$ rod that can be bent into place. Finally, some ridged materials can move through friction of the trigger, as is the case of the cookie shooter.

The five computational making characteristics are further summarized in Table 2, broken down per set per skill. The table highlights the presence of all aspects of computational making in all three LEGO sets.

\section{DISCUSSION}

The present analysis highlights the ways in which the three LEGO sets are designed in such a way to afford the application of computational making skills. They allow opportunities for children to experiment with aesthetics, creativity, constructing, visualizing multiple representations and understanding materials. This suggests computational making is a framework for assessing learning opportunities through STEAM in varied educational, making and play oriented environments.

While we do not evaluate the educational validity of the LEGO sets directly or look at how effective computational making is in educational terms, we have shown that kits marketed towards girls can be analyzed using a computational making framework with all its encompassing characteristics. It is heartening that despite the extensive critique of 'girly' LEGO, the sets do in fact allow for the teaching of the same making skills we expect to see 
Table 2. Computational making skills summary mapped per LEGO setup

\begin{tabular}{|c|c|c|c|c|c|c|}
\hline & & Aesthetics & Creativity & Constructing & $\begin{array}{l}\text { Visualizing Multiple } \\
\text { Representations }\end{array}$ & $\begin{array}{l}\text { Understanding } \\
\text { Materials }\end{array}$ \\
\hline $\begin{array}{l}\text { Fusion } \\
\text { Designer }\end{array}$ & Resort & $\begin{array}{l}\text { Buildings' aesthetics } \\
\text { can be customized } \\
\text { based on: } \\
\text { - layout } \\
\text { - } \quad \text { shape } \\
\text { - } \quad \text { colors } \\
\text { - } \quad \text { style }\end{array}$ & $\begin{array}{l}\text { Physical space: what } \\
\text { buildings to create } \\
\text { and the link between } \\
\text { aesthetics and } \\
\text { function } \\
\text { Virtual space: } \\
\text { imagination to build } \\
\text { a resort and the link } \\
\text { between resort } \\
\text { necessity and design. }\end{array}$ & 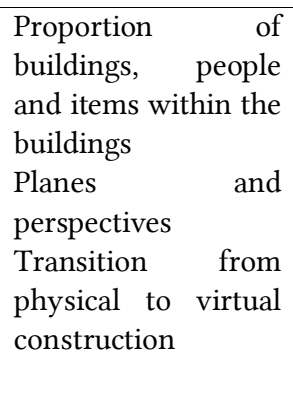 & $\begin{array}{l}\text { Enhanced virtual } \\
\text { representation of the } \\
\text { physical model } \\
\text { Multiple } \\
\text { representations of } \\
\text { different buildings } \\
\text { using the same base }\end{array}$ & $\begin{array}{l}\text { Associate physical } \\
\text { LEGO bricks to } \\
\text { materials used for } \\
\text { buildings in the } \\
\text { virtual world }\end{array}$ \\
\hline $\begin{array}{l}\text { Olivia's } \\
\text { Lab }\end{array}$ & Creative & $\begin{array}{l}\text { Customize layout of } \\
\text { desks around the lab, } \\
\text { desk items, charging } \\
\text { stations or } \\
\text { characters look and } \\
\text { responsibilities }\end{array}$ & $\begin{array}{l}\text { Personalization of } \\
\text { robots }\end{array}$ & $\begin{array}{l}\text { Robot building } \\
\text { equipment, charging } \\
\text { stations and other } \\
\text { elements needed in a } \\
\text { robotics laboratory }\end{array}$ & $\begin{array}{l}\text { Three distinct } \\
\text { representations: } \\
\text { - photo of final build } \\
\text { - brick within the set } \\
\text { itself with robot } \\
\text { schematic } \\
\text { - LEGO construction }\end{array}$ & $\begin{array}{l}\text { Blackboards, } \\
\text { screens, windows } \\
\text { are represented by } \\
\text { stickers. Any other } \\
\text { physical element can } \\
\text { be part of the solid } \\
\text { construction is a } \\
\text { LEGO brick. }\end{array}$ \\
\hline $\begin{array}{l}\text { Elvendale } \\
\text { of Dragons }\end{array}$ & School & $\begin{array}{l}\text { Limited in terms of } \\
\text { aesthetic } \\
\text { customizations but } \\
\text { heavily aesthetic as a } \\
\text { LEGO design set }\end{array}$ & $\begin{array}{l}\text { Playing teacher and } \\
\text { reinforcing values } \\
\text { on education }\end{array}$ & $\begin{array}{ll}\text { Engineering and } \\
\text { physics concepts: } \\
\text { - } \quad \text { gravity } \\
\text { - } & \text { speed } \\
\text { - } & \text { pivoting } \\
\text { - } & \text { propulsion }\end{array}$ & $\begin{array}{l}\text { Three distinct } \\
\text { representations: } \\
\text { 1) photo of final } \\
\text { build } \\
\text { 2) blackboard brick } \\
\text { within the set as a } \\
\text { piece of the project } \\
\text { with schematics } \\
\text { 3) LEGO } \\
\text { construction }\end{array}$ & $\begin{array}{l}\text { Drawings, actions } \\
\text { (flags moving in the } \\
\text { wind), or other non- } \\
\text { physical constructs } \\
\text { are either stickers or } \\
\text { other materials such } \\
\text { as the bendy zip line. }\end{array}$ \\
\hline
\end{tabular}

in boy's LEGO. Computational making skills become especially relevant in creating contraptions such as the dragon zip-line in the Elvendale School for Dragons. It would be interesting in future work to examine the relative frequency of these features in sets marketed to girls versus boys.

Comparing current LEGO sets marketed towards boys and girls respectively we see very different storylines with social motivations for their use [5]. In boy sets we see themes of warfare (the Star Wars or Ninjago line) or destruction (LEGO Bulldozer Set 60074 City Demolition) [5]. Each of these sets have complex mechanisms and contraptions to make weapons fire, or buildings collapse in exciting ways which in turn teach computational making. The girls' line Elves also has extensive use of mechanisms, but with different social motivations. The LEGO Elves Treetop Hideaway (set 41075) for instance includes a disappearing magic portal, a half barrel on pulley system to raise or lower people to the treehouse, a secret hiding place, a suspension bridge, a convertible sofa bed with leaf curtain that close for privacy [8]. These mechanisms are motivated by the Elves storyline and accompanying social motivations. Based on our personal experience assembling sets, we argue that often
LEGO girl sets rival or exceed boys sets in terms of computational making skills required to assemble them, and yet this complexity is rarely acknowledged.

Sarkeesian [16] in her extensive critiques of femininely gendered LEGO validly argues that aspects of these sets are problematic in that they reinforce reflection on binary gender roles. She argues it is troubling that boys sets focus on warfare, policing, and construction,

but largely lack living facilities and services needed for daily life, while at the same time girl's LEGO focuses on helping one another while baking, shopping relaxing, and taking care of animals [16]. The choice of domains reinforces a gender binary that insists some types of activities are for girls and others for boys, which in turn impacts the social skills developed through play. These are valid and important concerns.

At the same time, we find it disconcerting that these girl sets have not been seriously considered for their educational value. Just because a set is pink and purple, as we have shown here, does not mean it lacks the capacity for teaching computational making. The discussion around these sets is problematic in that by doing 
so they breakdown the stereotype of the a-technical femininity which we argue is also of value.

Further work is needed to attest to the educational value of these LEGO sets delivering the proposed computational making skills. A step further from the current analysis is needed towards understanding exactly to what extent such computational skills are taught when playing with 'girly' LEGO, and exactly how these manifest themselves for different children in different contexts.

\section{CONCLUSION}

In this paper, we have discussed the educational possibilities for teaching computational making with three LEGO kits. Of course, just because a kit's designers afford a possibility does not mean children master or even understand a computational making skill. After all, as discussed in the Giddings' research [6] some children open the box and begin free building immediately, discarding the instructions entirely. Consequently, future work should involve children and assess their learning attainments. However, our contribution here focuses on computational making as a framework for analyzing potential learning outcomes of making experiences, thus assessing educational attainment was not needed for this goal. We have shown that the computational making framework is broadly just as applicable for understanding skills needed to complete a LEGO project as an e-textiles project.

Further, we have shown that despite concern over the "Peril of Pink Bricks" [7] when dealing with LEGO sets marketed towards girls, these kits afford a full range of computational making skills. While prior work had not discussed the educational potential of LEGO sets marketed towards girls, this paper attempts to fill that gap. Thus, while there are certainly questions regarding what Harding [21] would call "individual gender" identity and "structural gender" identity constructed by the children who play with LEGO, they do allow the potential of children playing with them the developing the same range of skills as the boy's sets. Separate research is required on the way gender identity is formed when using LEGO, but we would argue, at minimum, these sets afford a space that allows "girly girls" to have experiences which link their femininity and computational making skills. The same holds for boys that want to draw on their feminine side. Given Faulkner's [15] concerns that STEM stereotypes are developed in a way that disallows simultaneous expressions of femininity and technical prowess, we would argue a safe space to make these connections is needed. Ultimately, you can learn as much from pink and purple LEGO bricks, as you can with red and blue ones.

\section{ACKNOWLEDGMENTS}

We would like to thank our reviewers, as well as, Anne Weibert, Andrea Marshall, Konstantin Aal, Thomas. von Rekowski, Houda El Mimouni Jennifer Booker and Volker Wulf for their collaboration on the initial Computational Making paper.

\section{REFERENCES}

[1] Valerie Barr and Chris Stephenson. 2011. Bringing computational thinking to $\mathrm{K}-12$ : what is Involved and what is the role of the computer science education community?. ACM Inroads. vol. 2. no. 1. pp. 48-54
[2] Rebecca W. Black, Bill Tomlinson and Ksenia Korobkova. 2016. Play and identity in gendered LEGO franchises. International Journal of Play. vol. 5. no. 1.pp. 64-76

[3] Friends Bricks. 2016. Elvendale School of Dragons Review. [Online]. Available at: http://friendsbricks.com/Elvendale-School-of-Dragons-Review.html. [Accessed at 31st January 2017]

[4] Sean Cubit. 2016. Aesthetics of the Digital. in a Companion to Digital Art, First Edition. Ed. Christine Paul. London, UK; John Wiley \& Sons

[5] Eliana Docterman. 2014. The War on Pink: GoldieBlox Toys Ignite Debate Over What's Good For Girls. Times. [Online]. Available: http://time.com/3281/goldie-blox-pink-aisle-debate/. [Accessed 2 February 2014]

[6] Seth Giddings. 2014. \&quot;Bright bricks, dark play: On the impossibility of studying LEGO. In: Wolf, M. J., ed. (2014) LEGO Studies: Examining the Building Blocks of a Transmedial Phenomenon. Routledge. New York

[7] Gry H. Knudsen and Erika Kuever. 2015. "The Peril of Pink Bricks: Gender Ideology and LEGO Friends. in Anastasia E. Thyroff, Jeff B. Murray, Russell W. Belk (ed.) Consumer Culture Theory (Research in Consumer Behaviour, Volume 17). pp. $171-188$

[8] Jangbricks. 2017. LEGO Elves: The Elves' Treetop Hideaway review! set 41075. [Online]. Available: https://www.youtube.com/watch?v=VTjhSQiWWa4. [Accessed 1 February 2017]

[9] Yasmin B. Kafai, Kristin Searle, Cristobal Martinez and Bryan Brayboy. 2014. Ethnocomputing with electronic textiles: culturally responsive open design to broaden participation in computing in American Indian youth and communities. in Proceedings of the 45th ACM technical symposium on Computer science education

[10] LEGO. 2017. Building instructions for 21208, LEGO® FUSION RESORT DESIGNER LEGO ONE REALITY. [Online]. Available: https://www.lego.com/enus/service/buildinginstructions/search?ignorereferer=true\#?search\&text=2120 8. [Accessed 31 January 2017]

[11] LEGO. 2017. Building instructions for 41173, ELVENDALE SCHOOL OF DRAGONS, LEGO ELVES. [Online]. Available: https://www.lego.com/enus/service/buildinginstructions/search?ignorereferer=true\#? search\&text $=4117$ 3. [Accessed 31 January 2017]

[12] LEGO. 2017. Building instructions for 41307, OLIVIA'S CREATIVE LAB, LEGO FRIENDS. [Online]. Available: https://www.lego.com/enus/service/buildinginstructions/search?ignorereferer=true\#? search\&text $=4130$ 7. [Accessed 31 January 2017]

[13] LEGO WIKI. 2017. Olivia. [Online]. Available: http://legofriends.wikia.com/wiki/Olivia. [Accessed 31 January 2017]

[14] Seymour Papert. 1980. Mindstorms: Children, computers, and powerful ideas. Basic Books

[15] Jennifer A. Rode, Anne Weibert, Andrea Marshall, Konstantin Aal, T. v. Rekowski, H. E. Mimouni and J. Booker. 2015. From computational thinking to computational making. In Proceedings of the 2015 ACM International foint Conference on Pervasive and Ubiquitous Computing (UbiComp '15) New York, NY, USA. pp. 239-250

[16] Anita Sarkeesian. 2012. LEGO Friends - LEGO \& Gender Part 1 \& 2. [Online]. Available: https://www.youtube.com/watch?v=CrmRxGLn0Bk\&feature=youtu.be. [Accessed 1 February 2017]

[17] Phaedra Shanbaum. 2017. The Interface Is Obsolete: A Critical Investigation of the Digital Interface in Interactive New Media Installations. Unpublished Thesis

[18] Anne Weibert, Andrea Marshall, Konstantin Aal and Jennifer A. Rode. 2014 Sewing interest in E-textiles: analyzing making from a gendered perspective. Proceedings of the 2014 conference on Designing interactive systems. pp. 15-24

[19] Anne Weibert and Volker Wulf. 2010. All of a sudden we had this dialogue...: intercultural computer clubs' contribution to sustainable integration. Proceedings of the 3 rd International Conference on Intercultural Collaboration

[20] Jeannette M. Wing. 2008. Computational thinking and thinking about computing Philosophical Transactions of the Royal Society A: Mathematical, Physical and Engineering Sciences. vol. 366. no. 1881. pp. 3717-3725

[21] Jeannette M. Wing. 2006. Computational thinking Communications of the ACM. vol. 3. no. 49. pp. 33-35 